\title{
Digital transformation of Eurasian Economic Union's (EAEU) logistics system
}

\author{
Vera Viktorovna Borisova, \\ Department of logistics and supply \\ chains management \\ Saint Petersburg State University of \\ Economics \\ Saint Petersburg, Russia, \\ verabrsv@yandex.ru
}

\author{
Natalia Sergeyevna Pechenko, \\ Department of logistics and supply \\ chains management \\ Saint Petersburg State University of \\ Economics \\ Saint Petersburg, Russia, \\ natalya-oteva@yandex.ru
}

\author{
Ayuna Vladimirovna Molonova, \\ Department of logistics and supply \\ chain management \\ Saint Petersburg State University of \\ Economics \\ Saint Petersburg, Russia, \\ aynamol@mail.ru
}

\begin{abstract}
This article is addressing the key items regarding digital transformation of export-import trade operations taking place while designing the logistics system of the Eurasian Economic Union (EAEU). Results of investigation enable the authors to reveal the problems occurring during creation of common market of logistics services and common digital space in countries having different sizes of economy, levels of economic development, conditions of logistics infrastructure and digital technologies. The authors are investigating the dynamics of development of export-import trade operations within EAEU. It is demonstrated that inconsistency of statistic data, document management system and logistics standards is adversely affecting integration in the sphere of trade. The paper is addressing the matters regarding the possibility to balance logistics and digital architecture of EAEU member-states within the framework of logistics system. The authors are proposing the model of integrating digital platform capable to provide interaction of logistics and digital technologies within EAEU. Such model is oriented towards optimization of export-import trade flows, increase capabilities to take sustainable solutions aiming to achieve strategic targets of thee EAEU logistics system (EAEU LS) development.

Model of integrated digital platform creates new possibilities enabling exchange of information among logistics system elements and external environment, allows undertaking instantaneous actions upon data acquisition from digital platform's sensors and coordinating center. Based on the generated online data array, end-to-end management of the entire value chain and monitoring of controlled performance indicators is carried out.

The paper made it possible to conceptually outline the problem associated with the so called "Single-window" mechanism based on equalization of logistics and digital architecture of foreign trade operations realized by the EAEU member states. Significance of the forwarded research is defined by the necessity to resolve the problem of identification of subject-object content, structure and specific features of the EAEU LS management in conditions of economy digitization.
\end{abstract}

Keywords - export-import trade operations, integration model, digital platform, supply chain management, digital logistics

\section{INTRODUCTION}

Economic nature of logistics allows regarding it as an integrative element of stabilization of reproductive relations in the economic systems characterized by various degrees of complexity [1]. Integration potential of logistics is implemented also in export-import trade operations whose optimization problems are referred to in dedicated section of international logistics.

Today's world trade is characterized by increasing complicacy of export-import trade operations. This is stipulated by a number of adverse factors the main of which consists in protectionist measures maintained by the USA, different forms of sanctions and restrictions against Russia and other targeted trade wars. Increasing protectionism considerably changed the established global supply chains. Different countries of the world, aiming to balance global trade flows and maintain global market strength, are uniting to form unions and associations so as to integrate their efforts in this direction [2].

International logistics and supply chains management are going through revolutionary transformations thus shaping the new digital paradigm of logistics. Foreign experience in the sphere of supply chains management shows that digitization is currently covering entire functional areas and key activities of logistics. Increasingly greater attention of scientists and practical persons is currently being drawn by digital transformations taking place within global supply chains $[3,4]$.

Scientists associate capabilities of export-import trade operations rationalization with creation of ecosystems of transport corridors and increasing of transportation capacities of EAEU member states [5]. Obviously, efficient international goods exchange assumes not only taking due account of regional and industry-related features of trade participants but also working out of unified economic ties establishment standards

A noteworthy detail is scientists' viewpoint regarding expediency of using the methods of strategic equalization of digital transformations taking place during formation of global supply chains [6].

Military logistics gave birth to network-centric management methods which are quite adaptive to global supply chains management [7].

A number of experts pay special attention to the necessity of applying convergent technologies [8] and inventions in the sphere of supply chains network design $[9,10]$ in the international trade.

Compilation of various viewpoints regarding digital technologies transformation in the international logistics shows that improvement of EAEU export-import trade operations becomes possible where it is resulting from member states' integration within the framework of platform- 
type macro-economic system operating with the use of "Single-window" mechanism and network-centric principles.

In modern economic conditions subsystems and elements of such complicated logistics system are integrated into organic whole by the digital flow. Let us define logistics system of Eurasian Economic Union as a large and complex socio-economic structure bringing together the totality of international trade subsystems and elements (interconnected and linked with environment) which make it possible to achieve system-wide targets on the basis of integration of export-import goods flows coordinated within the framework of digital platform.

As a matter of fact, this refers to logistics system of digital type where export-import good flows are acquiring the format of digital substance to form a "totality of communication technologies, regulators of digital transformations, networks, messengers, cloud technologies and platforms" [11].

Virtual form of export-import good flows organization is the initial concept for EAEU logistics system. An important purpose in this system is allotted to integrative constituent and formation of the single information space (digital platforms) with the use of cloud technologies and artificial intelligence. In such case, system's endogenous processes are not only complementing one another but are also dovetailing with environmental changes on the following principles: (i) global access to resources without intermediaries, (ii) offering resources for lease, (iii) use of voluntary services and (iv) network-centric management [12].

Successfulness of EAEU LS is strongly dependent on actions coordination among the parties involved. Such coordination may be ensured by the "Single-window" mechanism and intelligent applications thereto [13].

Forms of digital space organization may take the shape of a digital platform being "special communication environment enabling (i) on-line acquisition, generation, analysis of data disclosing the status of supply systems, (ii) forecasting of system elements' qualitative and quantitative condition, (iii) timely undertake preventive measures in order to avoid faults. In the aggregate, it allows considerably (by times) improving system efficiency and reducing (by ten folds) system administration costs" [11, p.24].

\section{METHODOLOGY}

The goal of EAEU LS's digital transformation puts forward particular requirements to the model representation of these processes. Research methods must (i) demonstrate degree of formalization sufficient for establishment of meaningful relationships and dependencies, (ii) have a high level of adaptivity depending on the status of the functional system (subsystem, element), (iii) enable practical implementation thereof in conditions of changing environment.

Worth mentioning publications dedicated to this problem are: (i) general methods of mathematical modeling in economics, (ii) components of simulation modeling used for solving the multi-functional logistics problems (neural networks, fuzzy logics, evolutionary computations). Researchers are drawing attention to the use of analytical applications and artificial intelligence in the strategic management of supply chains with a purpose to improve stability and balance of inter-organizational cooperation among the system participants in conditions of fierce competition [11].

It should be noted that currently used methods and models only partially meet these requirements. The method we have introduced assumes a symbiosis of the graphic modeling language and the tools for strategic alignment of the foreign economic activity of the EAEU logistics system participants. Such symbiosis expands opportunities of demands decomposition at the stage of EAEU LS structure elements formation and brings strategic and operating activities of logistics together.

Strategic equalization and integration of EAEU LS participants is fulfilled by coordinating logistics Center. Proposed multi-criteria model of digital platform consists of (i) coordinating logistics Center, (ii) secure information and telecommunication system, (iii) subsystems and links of the logistics system (generating, transforming and uptaking material and concurrent flows) integrated in unified digital environment with established parameters and operating in real-time mode.

Let us perform formalization of the given model for the purpose of strategic equalization with the use of theory of graphs earlier addressed to. For this purpose, let us represent it as a set of managerial tasks to be solved $\mathrm{E}=\left\{\mathrm{E}_{\mathrm{i}}\right\}, \mathrm{i}=1, \overline{\mathrm{I}}$, where each task may comprise $\mathrm{q}_{\mathrm{i}}$ stages and have $\mathrm{d}_{\mathrm{i}}$ alternate solutions within EAEU LS. Let us plot the links between tasks and their stages in the form of graph as follows $G_{c}=$ $\left\{\mathrm{E}_{\mathrm{qi}},\left(\mathrm{E}_{\mathrm{qi}}, \mathrm{E}_{\mathrm{q}}^{\prime}\right)\right\}$, where $\mathrm{E}_{\mathrm{qi}}, \mathrm{E}_{\mathrm{q}}^{\prime} \in \mathrm{E}$.

In such case, edges of the graph $\left(\mathrm{E}_{\mathrm{qi}}, \mathrm{E}_{\mathrm{q}}^{\prime}\right)$ are (i) characterizing succession relations existing between tasks to be solved and stages thereof and (ii) corresponding to the directions of export-import good flows.

Let us designate the set of potential logistics system links as follows: $\quad \mathrm{M}=\left\{\mathrm{M}_{\mathrm{i}}\right\}$, and specify links between them as a graph $\mathrm{G}_{\mathrm{m}}=\left\{\mathrm{M}_{\mathrm{j}},\left(\mathrm{M}_{\mathrm{j}}, \mathrm{M}_{\mathrm{j}}^{\prime}\right)\right\}, \mathrm{j}, \mathrm{j}^{\prime}=1, \mathrm{j}$. In such case, graph points are forming the nodes (EAEU LS links) while graph edges represent connections between them. Based on this, as an optimization criterion for the vector objective function, we take the extremum of the exponent $\mathrm{U}$, which is reflected by the following formula:

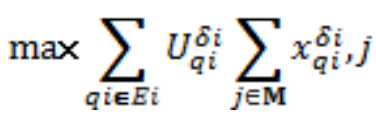

[with $\mathrm{E} \in \mathrm{E}, \mathrm{M} \in \mathrm{M}, \mathrm{G}_{\mathrm{c}} \in \mathrm{G}_{\mathrm{c}}, \mathrm{G}_{\mathrm{m}} \in \mathrm{G}_{\mathrm{m}}$ ]

Where $U_{q i}^{\delta i}$ - an effect of i-task's q $\mathrm{q}_{\text {-stage }}$ implementation while using $\delta_{\mathrm{i}}$-option of solution.

$x_{q i}^{\delta i} j$

- a binary variable will take value 1 where $\mathrm{q}_{\mathrm{i}}$ stage of i-task with $\mathrm{d}_{\mathrm{i}}$-option of implementation is solved in j-link of EAEU LS and take value 0 otherwise.

At that, restrictions in respect of material, financial, information, labor resources etc. are taken into consideration.

In such case, managerial effect provided by coordinating logistics Center for EAEU LS will be maximized by retrieving $M$ system nods and connections between them $\left(\mathrm{G}_{\mathrm{m}}\right)$, set of logistics management tasks (E) and their solution options $\delta_{\mathrm{i}}, \mathrm{i}=1, \overline{\mathrm{I}}$ and by tasks allocation in EAEU LS subsystems and links so as to enable strategic cooperation among the participants and fulfill the declared objective function i.e. achieve maximum effect of logistics 
management provided for EAEU LS export-import good flows.

Thus, strategic goal of EAEU LS is correlated with demand to equalize parameters of system participants' operating activities with provision of conformance to strategic local goals.

\section{FINDINGS}

Formation of EAEU LS's digital platform is performed with the use of the "Single-window" mechanism and artificial intelligence technologies.

Different analytics evaluate the prospects of logistics system intellectualization in different ways. Most part of them draws attention to increasing growth of software intended for artificial intelligence. If to take into account global economy - anticipated growth is 42 times, i.e. from USD 1.4 billion in 2016 to USD 59.8 billion in 2025 [14].

Artificial intelligence technologies are expected to transform the way of interaction of logistics system participants between each other and with software products. Virtualization of logistics activities and creation of intelligent logistics systems is the result of coordinated employment of artificial intelligence -based technical and sensor devices. By 2021 experts are forecasting rapid evolution of the content and applications landscape of virtual and augmented reality technologies. These technologies will begin merging with digital networks to create closely interconnected device systems capable to regularize information flows transmitted to the users through customized and relevant applications and services.

Cooperation of EAEU LS participants with the digital platform-embedded artificial intelligence will considerable expand mobile applications use opportunities. Integration of media on the basis of various mobile and portable devices, IoT and sensors will create the possibilities to use multichannel applications in logistics activities.

In other words, intellectual structure of the "Single window" mechanism will integrate elements-links of EAEU LS to form digital platforms and provide software products, computational resources and services enabling data storage in "cloud" information pool to all of its participants. Objective model of the "Single window" mechanism is designed to provide cloud service management within the integrated platforms.

Digital platform manager designates: audit events; expected results and positive effects of the EAEU LS development. Actually, the project of general-purpose digital platform employment is being fulfilled. Noting the advantages of super sophisticated digital platform-based logistics systems to which the EAEU LS may be referred let's point out their informational oversaturation which may create a threat for well-balanced system development.

In the recent times the new model of network-centric logistics system has been formed [7]. Analysis shows that the EAEU LS is based on network-centric principles providing coordination of activities, proper decision-making time and elements integrity within unified geographically dispersed environment. Main components of such system are: (i) digital platform (information grid) providing on-line access to any required information for entire participants, (ii) digital technologies applied (namely - their actuality, flexibility and maneuverability and (iii) integrated sensor-based matrix (communications net). Obviously, well-balanced functioning of entire constituent components comprising such system assumes compatibility of information used by its participants and software products.

Self-synchronization of the logistics system allows promptly starting parallel activities of elements-links and thus creating the basis for information supremacy principle implementation. As a result, information supremacy of such logistics system allows achieving goals, adapting to changing environmental parameters and predicting potential risks farforth promptly and efficiently. Territorial dissociation of the EAEU LS elements is not capable to adversely affect its functioning results due to digital platform's intelligent interface which is coordinating inter-organizational and inter-functional relations.

\section{DISCUSSION}

Studying the abilities of model representation of logistic integration of the EAEU member states and prospects of digital transformation of export-import trade operations performed within logistics system network we based ourselves upon mature theories, methods and tools. Analysis indicates that it is possible to design the model of the EAEU logistics integration through creation of integrated digital platform comprising informative, sensor and operative packages.

According to expert estimates, digital platforms of this type enable reduction of transport-logistics complex costs optimization by $55 \%$, on the average, through intellect-based plotting of routes, documents management system digitization, use of multimedia, software and artificial intelligence technologies [13].

For the EAEU member states this digital platform may become a tool allowing solving the problem of border check points overload and thus accelerate customs procedures for export-import operations making them more transparent and flexible.

Currently, there are barriers which impede launching of integration processes in digital platform format. The following ones may be pointed out: "relatively low economic potential of the EAEU member states resulting from insufficient level of economic development and competitiveness, de-industrialization tendencies, primitive economic structure, distortion of reproductive performance; incompleteness of common economic space, remaining regional barriers for free movement of productive factors including infrastructure and foreign currency restrictions; considerable differentiation in the level of the EAEU member states' economic and financial markets development, their structural promiscuity, discrepancies in legal regulation of economic activities, regulation practices and supervision; deficit of financial resources" [15].

Different levels of the EAEU member states' logistics infrastructure including transport, warehousing and customs also deserve consideration. Thus, considerable differences in transport logistics development are observed in Russia, Belarus and Armenia [16].

Assessment of prospects of digital platform-based integration processes allows concluding that elaboration of the EAEU LS digitization measures may be based on the modified model of strategic equalization of trade business processes and digital transformations fulfilled. Analysis of prospects of digital platform-based integration processes shows that existing sub-systems and links of the EAEU LS 
(logistics infrastructures, branches of industry, business structures, governmental bodies and human resources) have weak interconnections, different level of development and poor level of readiness to digital transformations.

In order to coordinate transition to the mode of consistent interaction the system participants require continuous monitoring and control of transformations on the part of existing consulting authorities (for example, consulting Committee for transport and infrastructure). However, it is expedient to expand powers and logistics competences vested in such Committee in regard of controlling the objects of infrastructure, customs administration, state procurements etc. One of mandatory requirements regarding logistics processes harmonization and export-import operations rationalization is the "Single window" mechanism employment. Approbation of the above mentioned initiative may be implemented within the framework of the pilot project of business, state and public sector's resources mobilization on the crowd sourcing platform with a purpose of ideas and experience exchange with the use of digital technologies (in the format of digital "sand pits" and startups)

In discussions about the order of priority in the EAEU logistics systems digital transformation special focus is made on artificial intelligence investigation methods: conventional (machine-based) and computational (iterative, trainable). The use of the aforesaid methods allows fulfilling (independently and promptly) millions of transactions, analyze reports presented by trade agents, prioritize the suppliers, generalize social networks information etc. [17, 18, 19].

Overarching goal of using the artificial intellect-based methods in the EAEU logistics system is its intellectualization and improvement of functional capabilities enabling issuing of optimized non-formalized managerial solutions commensurable with or even outstripping the human capacities. Electronic devices used in such systems and identified as intelligent applications perform a part of logistics management functions and involve artificial intelligence to acquisition, processing and analysis of huge amount of data [11].

Virtual specialized applications intended to perform particular tasks like casting and delivery of goods, client service etc. are already created and are being currently integrated into logistics practices. Such intelligent applications are designed to essentially reverse the nature of logistics activities and transform the structure of logistics system [20].

Physical things operating in the framework of hard coded models using artificial intelligence and machine tools acquire new roles within the intelligent logistics system. Such intelligent things are designed to fulfill complicated logistics functions and capable to demonstrate quite natural interaction with logistics environment. "Smart" things may be equipped with sensors, accelerators, keyboard, optic fiber, heating elements, solar batteries, players and other devices. Progressively as intelligent devices are being used in logistics practices (unmanned aerial vehicles, driverless road transport etc.) it is expected that there will be shifting from autonomous intelligent things employment to co-utilization. Opportunities in this field will definitely expand the capacities of virtual and augmented reality technologies.

\section{CONCLUSION}

Analysis of the EAEU LS transformation shows that activities carried out in this sphere are stipulated by integration of a large number of export-import trade operations, industry-related, inter-institutional and international databases into unified digital environment and by reconfiguration of global supply chains.

Hypothesis has been verified that qualitative stability and reliability of connections among territorially detached elements-links of the EAEU LS are considerably limited by their informative dissociation. Implementation of multicriteria model of integrated digital platform intended to ensure strategic equalization and efficiency improvement for its participants' foreign economic activities may become the quality guarantor of the EAEU LS digital transformations.

Digital platform becomes the key component connecting elements-links of the EAEU LS to ensure system participants consolidation in the following aspects: robotization, automation, advanced analytics, software support for the informative-technological infrastructure etc.

\section{RECOMMENDATIONS}

Analysis shows that digital transformation of the EAEU LS is accompanied by positive and negative effects. Therefore, at the stage of the EAEU LS design it is essential to determine critical digital infrastructures (jointly used and supporting integration processes), elaborate general procedure providing their information security including (if necessary) development and implementation of international security protocols and procedures enabling joint digital platforms utilization.

\section{REFERENCES}

[1] Bowersox D., Kloss D., Logistics: Integrated Supply Chain, 1st edn. (Moscow, ZAO Olymp-Business, 2008), 640 p.

[2] Borisova V.V., Pechenko N.S. Integration and coordination of logistics flows in Eurasian Economic Union //Messenger of Rostov State Economic University No.1(65) March, 2019. p. 27-25.

[3] Demin A.S. Influence of regional differences on trans-national corporations' supply chain management. // Logistics and supply chains management. No. 2 (91), 2019. p. 15-27.

[4] Maydanova, S., Ilin, I. Problems of the preliminary customs informing system and the introduction of the Single Window at the sea check points of the Russian Federation (2018) MATEC Web of Conferences, 239, статья № 04004.

[5] Plastunyak I.A. Logistics system of EAEU: decomposition, coordinated management. // "Logistics: modern tendencies of development", Papers of XVIII international research to practice conference, Part 2, 2019. Saint Petersburg admiral Makarov State University of maritime and inland shipping, -p.49-54.

[6] Kudryavtsev D.V., Grigoriev L.Yu., Kubelskiy M.V., Bobrikov S.A. Method of strategic equalization of company activities based on quality function deployment technology.//Messenger of Saint Petersburg State University. Management. Vol. 17. issue 4, 2018. p.465-495.

[7] Borisova V.V. Logistics systems: from hierarchy to networkcentricity "Logistics: modern tendencies of development", Papers of XVIII international research to practice conference, Part 1, 2019. Saint Petersburg admiral Makarov State University of maritime and inland shipping p. 53-56.

[8] Kovalchuk M.V. Convergence of sciences and technologies breakthrough to the future//Russian nanotechnologies. Vol. 6 No. 12/2011. p.13-23.

[9] Sergeyev V.I. Design of supply chains network structure.// Logistics and supply chains management. No 3(86), June 2018. p. 20-34. 
[10] Levina, A.I., Dubgorn, A.S., Iliashenko, O.Y. Internet of things within the service architecture of intelligent transport systems (2018) Proceedings - 2017 European Conference on Electrical Engineering and Computer Science, EECS 2017, pp. 351-355.

[11] Afanasenko I.D., Borisova V.V. Digital logistics: Textbook for higher education institutions. - Saint Petersburg: Piter, 2018.- p. 272.

[12] Abdikeyev N.M., Ivaniuk V.A., Pashchenko F.F., Gribeva N.V. Network-centric methods of management / Management sciences. No 1, 2017. p. 26-34.

[13] Pechenko N.S. Shaping and evolution of the EAEU digital environment. //Modern management: problems and prospects: collection of articles of XIV international research to practice conference "Modern management: problems and prospects" / under the editorship of doctor of economics, professor Ye.A. Gorbashko, doctor of economics, professor I.V. Fedoseyev. - Saint Petersburg. : Publishing house of Saint Petersburg State University of Economics, 2019 p. 782-784.

[14] Report by McKinsey "Digital Russia" : new reality. Access mode: http://www.mckinsey. /global-locations/europe- andmiddleeast/russia/ru/our-work/mckinsey-digital Accessed December 2018

[15] Alexeyev P.V. Tendencies and prospects of shaping the common financial market for the EAEU member states. No. 1 (170), 2019. p.109-113.

[16] Duisenbai D.T., Domnina S.V. EAEU countries entering the new phase of forming the Unified transport space.// Logistics and supply chains management. No.5(88), 2018, p. 3-13.

[17] Brink H., Rischards J., Feverolf M. Machine learning, Saint Petersburg: Piter, 2017. p.336.

[18] Russel S., Norvig P. Artificial Intelligence Modern approach, issue 2. - Moscow: Williams, 2007. p. 1410.

[19] Rashid T. Creating the neuron network, Saint Petersburg: Alfa book, 2017. p. 274.

[20] Lukinskiy V.S., Serova Ye.G. Methods and tools enabling intelligent data analysis in digital logistics and supply chains management//Logistics and supply chains management. No.4(87), August 2018, p.73-80. 